\title{
Medication for Attention Deficit-Hyperactivity Disorder and Criminality
}

Paul Lichtenstein, Ph.D. ${ }^{1}$, Linda Halldner, M.D., Ph.D. ${ }^{1}$, Johan Zetterqvist ${ }^{1}$, Arvid Sjölander, Ph.D. ${ }^{1}$, Eva Serlachius, M.D., Ph.D. ${ }^{2}$, Seena Fazel, M.B., Ch.B., M.R.C.Psych., M.D. ${ }^{3}$, Niklas Långström, M.D., Ph.D. ${ }^{1}$, and Henrik Larsson, M.D., Ph.D. ${ }^{1}$

${ }^{1}$ Department of Medical Epidemiology and Biostatistics, Karolinska Institutet, Stockholm, Sweden

${ }^{2}$ Department of Clinical Neuroscience, Karolinska Institutet, Stockholm, Sweden

${ }^{3}$ Department of Psychiatry, University of Oxford, Oxford, UK

\begin{abstract}
Background-Attention deficit hyperactivity disorder (ADHD) is a common disorder that is associated with criminal behavior. Pharmacological treatment is available for ADHD and may reduce the risk of criminality
\end{abstract}

Methods-We gathered information on all individuals with a diagnosis of ADHD ( $\mathrm{N}=25,656)$, their pharmacological treatment, and subsequent criminal convictions in Sweden during 2006 to 2009 using Swedish national registers. We used stratified Cox regression analyses to compare the rate of criminality while on ADHD medication, compared with the rate for the same individual while off medication.

Results-Compared to non-medication periods, the criminality rate while on medication was significantly decreased by $32 \%$ (stratified Cox Regression hazard ratio: $0.68 ; 95 \%$ confidence interval: $0.63-0.73$ ) for men and $41 \%$ (hazard ratio: $0.59 ; 95 \%$ confidence interval: $0.50-0.70$ ) for women. The rate reduction remained between $17-46 \%$ in sensitivity analyses among males, including different exposures (e.g., type of treatment - stimulant and non-stimulant) and outcomes (e.g., type of crime - less severe, violent, and substance-related conviction).

Conclusions-We found statistically significant associations between ADHD medication and criminality in within-individual comparisons, with lower rates of criminality observed during periods on treatment. These findings raise the possibility that medication treatment reduces the risk of criminality among patients with ADHD.

\begin{abstract}
About $5 \%$ of all children in the Western world fulfill diagnostic criteria for $\mathrm{ADHD}^{1}$ and a large proportion of these are treated pharmacologically ${ }^{2}$. ADHD is associated with criminality ${ }^{3,4}$ and externalizing disorders ${ }^{5}$. Beneficial short-term effects of ADHD medication on symptoms of ADHD and associated conduct problems have been demonstrated in numerous randomized controlled studies with children ${ }^{6-8}$ and adults ${ }^{9-11}$. ADHD symptoms are largely persistent from childhood into adulthood ${ }^{12}$, but one prominent feature of ADHD-treatment is that medication discontinuation is common ${ }^{13,14}$, especially in adolescence and early adulthood ${ }^{15}$. The importance of treatment discontinuation for criminality and other longer-term outcomes is largely unknown.
\end{abstract}

Correspond with Dr. Lichtenstein at the Department of Medical Epidemiology and Biostatistics, Karolinska Institutet, Box 281, 17177 Stockholm, Sweden. +46-8-5248 7424. paul.lichtenstein@ki.se..

Disclosure: Disclosure forms provided by the authors are available with the full text of this article at NEJM.org. 
The Multimodal Treatment of Attention Deficit Hyperactivity Disorder (MTA) study is the largest randomized clinical trial of ADHD medication with long-term follow-up ${ }^{16-19}$. The most sensitive measures of treatment (a composite of parent and teacher rated ADHD symptoms) suggested that the benefit of medication at the 14-month assessment had diminished at 36-months ${ }^{20}$. No association was observed with early delinquency and substance use at 36-months ${ }^{19}$. Although the study did not suggest long-term effects of medication, high rates of treatment discontinuation, lack of non-treated comparison groups, and limited range of outcomes mean that the longer-term effects of ADHD medication remain uncertain.

We used Swedish population-based data to investigate the association between ADHD medication and criminality.

\section{Methods}

Data were derived through linkage of population-based registers in Sweden; unique personal identification numbers enabled accurate linkage ${ }^{21}$. We identified all individuals born 1990 or earlier with at least one diagnosis of ADHD (ICD-9: code 314; ICD-10: code F90) in the Patient Register ( $\mathrm{N}=16,087$ males and 9,569 females), which includes all psychiatric hospitalizations since 1973 and outpatient diagnoses since $2001^{22}$. We also used the Prescribed Drug Register, which includes information on all prescribed medications since July $2005^{23}$. A general population sample, matched 1 to 10 on age, sex, and geographic location at the time of the diagnosis was used to contrast rates of criminality and medication use between patients with an ADHD diagnosis and the general population.

Criminality was identified through the National Crime Register, including convictions in district courts since $1973^{24}$, and the Register of Persons Suspected of Offenses, which records individuals suspected of crime after completed investigation by police, customs authority or prosecution service ${ }^{24}$.

To account for migrations, deaths, and imprisonment we linked to the Migration, Cause of Death, and Prison Registers. Periods in closed institutional youth care were estimated using conviction data in the National Crime Register.

\section{Measures}

The main exposure was ADHD medication identified in the Prescribed Drug Register using the Anatomical Therapeutic Chemical (ATC) classification system. Before 2008, ADHD medication could be prescribed only by child and adolescent psychiatrists, neuropediatricians or physicians licensed following individual application and Medical Products Agency approval. Since then, all specialists in psychiatry are licensed to prescribe. Nevertheless, ADHD medication to both children and adults has increased exponentially since $2005^{14}$. Methylphenidate (N06BA04) is recommended for first-line drug treatment, whereas amphetamine (N06BA01) and dexamphetamine (N06BA02) are more rarely prescribed. The non-stimulant atomoxetine (N06BA09) is also regularly used ${ }^{14}$.

In accordance with previous studies ${ }^{14,15}$, an individual was defined as receiving treatment during the time interval between two prescriptions of ADHD medication, unless prescriptions occurred more than 6 months apart. Thus, a treatment period was defined as a sequence of prescriptions, with no more than 6 months between two consecutive prescriptions. The start of treatment was defined as the date of the first prescription and end of treatment as the date of the last prescription. During intervals of 6 months or more without any prescriptions, an individual was considered to be off treatment. Patients receiving only one prescription $(\mathrm{N}=914)$ were considered to be off treatment. To determine 
whether individuals were receiving treatment at start and end of follow-up, the follow-up period was set to $1 / 1 / 2006$ to $12 / 31 / 2009$ as the Prescribed Drug Register only covered the period 7/1/2005 to $6 / 30 / 2010$.

The main outcome was any conviction for a crime. If no date of crime was recorded, the date of the conviction was used. In sensitivity analyses, we also investigated less severe (i.e., not associated with custodial sentences), violent, and substance-related crimes ${ }^{25}$ (for crime categories and prevalence see Table 1).

Individuals diagnosed with conduct, oppositional defiant, antisocial personality, or substance abuse disorders were identified through the Patient Register (ICD-9: 313.81, 312, 301.7, 291, 292, 303, 304, 305; ICD-10: F91, F60.2 and F10-F19).

\section{Statistical Analyses}

Here we provide a brief description of the statistical methods; a thorough description can be found in the Appendix. In all analyses, medication was treated as a time-varying covariate. To describe crude (i.e. unadjusted) associations between ADHD medication and criminality, we calculated "extended" Kaplan-Meier curves for time-varying covariates ${ }^{26}$. This analysis can be viewed as a non-parametric analog to Cox-regression with time-varying covariates. If the conviction rate is independent of previous medication, given current medication, then the extended Kaplan-Meier curves can be interpreted as estimated survival functions for individuals who don't change their medication status during follow-up ${ }^{27}$. To quantify the crude association between medication and criminality, Cox-regression hazard ratios (HRs) were used, with robust standard errors accounting for the correlations between periods within the same individual ${ }^{28}$.

Next, we performed "within-individual analyses", using stratified Cox Regression, adjusted for age, previous number of convictions, and previous number of medication switches as categorical variables in the model. In stratified Cox regression, each individual enters as a separate stratum in the analyses. Thus, each individual serves as his/her own control, and provided that the regression model is correct, these analyses adjust for confounders that are constant within each individual during follow-up (e.g. genetic make-up and childhood environment).

\section{Sensitivity analyses}

Associations between medication and criminality may be due to some patients starting a medication period when they have decided to make a significant change in their lives. We addressed this by investigating whether associations with criminality were different when patients went from a treatment to a non-treatment period compared with when they went from a non-treatment to a treatment period. We used individuals with consecutive periods with different medication status, and estimated the difference in risk for criminality for nontreatment periods versus treatment periods. Confidence intervals were estimated by nonparametric bootstrapping. We also examined whether these associations were consistent depending on if it was the first or second time a patient was prescribed ADHD medication.

To understand if observed associations could be explained by selection and to test the robustness of our results, we performed 9 post-hoc analyses including different exposures (stimulant, non-stimulant treatment) and outcomes (less severe, violent, substance-related convictions).

We did sensitivity analyses with a cohort of individuals that did not necessarily have an ADHD diagnosis in the Patient Register. Instead, the Prescribed Drug Register was used to identify individuals with at least one prescription for ADHD medication during follow-up. 
This was done to avoid selection bias as some counties have historically been less consistent in reporting outpatient data to the Patient Register.

The patients in our main analyses had ADHD reported to the Patient Register by a specialist physician. Sensitivity analyses were therefore performed in a cohort diagnosed in general child and adolescent mental health services also by psychologists or other non-medical specialists. For this, we linked to the Pastill Register, which includes patients diagnosed according to DSM-IV and/or ICD-10 since 2001 within Child and Adolescent Mental Health Services in Stockholm County ${ }^{29}$.

ADHD is often co-morbid with conduct, oppositional defiant, antisocial personality or substance abuse disorder ${ }^{5}$. It is not entirely clear if these should be regarded as confounders, mediators or colliders ${ }^{30}$. Thus, to test whether the association between medication and criminality was different depending on co-morbid diagnoses, we did a sensitivity analysis including only those without a comorbid disorder.

In Sweden individuals are convicted regardless of mental disorder, although sentencing will be influenced by psychiatric evidence. Nevertheless, the probability of receiving a conviction might be dependent on socioeconomic conditions, living area, or the age or psychiatric history of the individual. Therefore, we did sensitivity analyses with individuals suspected (rather than sentenced) for offenses.

To test whether associations were restricted to ADHD medication, we also performed sensitivity analyses with individuals who discontinued selective serotonin reuptake inhibitors (SSRI; instead of ADHD medication).

\section{Long-term associations}

To investigate long-term associations, a Cox regression was performed for the period January-December 2009, with medication status at 1/1/2006 as the main exposure. Age and medication during 2009 were adjusted for as time-dependent covariates.

The project was approved by the Ethics committee at Karolinska Institutet.

\section{Results}

We investigated 16,087 men and 9,569 women with ADHD (see Table 1 for descriptive data at baseline and during follow-up). Among men diagnosed with ADHD, 53.6\% had taken ADHD medication and $36.6 \%$ were convicted for at least one crime during follow-up. The corresponding figures for the matched general population controls were $0.2 \%$ and $8.9 \%$, respectively. Among female patients, $62.7 \%$ had taken ADHD-medication and $15.4 \%$ were convicted for at least one crime (Table 1), compared to $0.1 \%$ and $2.2 \%$ among controls.

In patients with ADHD, crimes occurred less often during periods with ADHD medication (Figure 1). The estimated probability of not being convicted for a crime during 4 years for those on medication during the entire period was 0.49 for males and 0.75 for females (689 [4.3\%] men and 368 [3.9\%] women were on medication during the entire period). The same probability while off medication was 0.37 and 0.69 respectively (7,468 men and 3,573 women were never on medication). The Cox regression hazard ratio (HR) was 0.70 (95\% confidence interval [C.I.]; 0.66-0.75) for males and 0.78 (C.I. 0.68-0.90) for females (Table 2), indicating that medication was associated with lower criminality rate.

Since patients receiving medication might be different from non-medicated patients, a critical test of the association is whether there are differences in crime rates in the same individual comparing medication and non-medication periods. The stratified Cox Regression 
estimates of the within-individual HRs were $0.68(\mathrm{p}<0.0001)$ for men and $0.59(\mathrm{p}<0.0001)$ for women (Table 2), suggesting that even within an individual (i.e., after adjusting for all confounders that are constant within the individual), medication reduced the criminality rate with $32 \%-41 \%$.

\section{Sensitivity analyses}

Because of the clear association between medication and criminality rate, we performed a series of sensitivity analyses. These were with males only, because of their higher prevalence of ADHD and criminality. Within individuals who had been both on and off medication, the risk for being convicted of any crime was significantly increased by $12 \%$ (C.I. 11.8-12.3) during a non-treatment period compared to when under treatment (Table 3). The increased risk remained when patients moved from no medication to medication status $(16 \%)$, and in the opposite direction (6\%). The risk remained significant regardless of whether it was the first or second time patients had their medication altered (Table 3).

We found similar reductions in criminality rates regardless of whether the ADHD medication was stimulants $(\mathrm{HR}=0.66)$ or non-stimulants $(\mathrm{HR}=0.76)$, and when analyses were restricted to less severe or specific crimes (Table 4).

The hazard ratios did not materially change when individuals were identified solely based on prescriptions $(\mathrm{HR}=0.64)$, from general child and adolescent mental health services based on the Pastill register $(\mathrm{HR}=0.83$ ), and when individuals with comorbid conduct, oppositional defiant, antisocial personality, or substance abuse disorders were excluded $(\mathrm{HR}=0.67)$, although the estimate did not reach statistical significance when using the Pastill register (Table 4). When the outcome was changed to suspicion of any crime, a reduction in criminality rates during ADHD medication was also found $(\mathrm{HR}=0.81)$. We found no evidence of an association when we investigated SSRI instead of ADHD medication $(\mathrm{HR}=1.04$; C.I. 0.93-1.17).

\section{Long-term associations}

Finally, we addressed long-term associations by exploring the medication status in 1/1/2006 and criminality rates during 2009 . No statistically significant associations were detected neither before (HR=0.84; C.I. 0.69-1.03) nor after (HR=0.94; C.I. 0.83-1.07) adjustment for medication in 2009.

\section{Discussion}

There has been considerable debate over the net effects of pharmacological treatment of patients with ADHD, where benefits on ADHD-symptomatology should be weighed against risks of side effects ${ }^{31,32}$, potential over-prescription, and development of tolerance, dependence or addiction ${ }^{32,33}$. Corroborating previous randomized short-term follow up studies of ADHD-symptoms and associated conduct problems ${ }^{6-11}$, we found associations suggesting the possibility of a protective effect of ADHD medication on concurrent rate for all types of criminality, and no statistical significant long-term reduction in crime rate following termination of medication. Among men, the crime rate was $32 \%$ lower $(\mathrm{p}<0.0001)$ during ADHD medication, and the rate reduction was $17-46 \%$ in all 9 sensitivity analyses; 8 of them significant. We observed a similar association among females $(41 \% ; \mathrm{p}<0.0001)$.

To avoid possible bias from reverse causation (i.e., that individuals stop treatment because of their criminal behavior, rather than the other way around), we investigated if the order of change in medication status was important. The associations were significant regardless of the order. 
Our main analyses did not address if there are only concomitant associations, or if criminality rates are affected beyond treatment termination. It is possible that pharmacological ADHD treatment help patients to better organize their lives and/or contribute to enduring changes at the neuronal level ${ }^{35}$. Another possibility is that the concomitant associations with treatment do not persist, which could be an explanation for previous lack of long-term effects ${ }^{17}$. In line with the latter possibility, we found no statistically significant persistent association between medication in 2006 and crime during 2009 , an interpretation also supported by our finding of associations between medication and criminality regardless of whether it was the first or second time the patients changed their medication status.

Unlike randomized controlled trials, pharmaco-epidemiological studies like ours are liable to confounding by indication; that is, patients on treatment are on treatment because they are different (usually more symptomatic and with comorbid conditions) ${ }^{34}$. Our within-

individual analyses were designed to account for confounders that remain constant for each individual (most importantly genetic and early environmental factors). However, unmeasured confounders and mediators related to prescribing drugs (e.g., alcohol binges, engagement with services that provide prescriptions or supportive partners who collect the prescriptions) rather than effects of the drugs can never be excluded in this research design. To address this we analyzed criminality rates among individuals who discontinued SSRI (instead of ADHD medication); we found no evidence of an association with SSRI discontinuation. In contrast to ADHD medication, other common psychotropic drugs have very different patterns of use as well as onset and end of effect. Thus, they could not be included as time-dependent covariates in our study, but at the same time, this will make it unlikely that psychotropic (or other) medication would have the potential to explain the concomitant association between ADHD medication and criminality. Selection effects might also occur due to the facts that the registration of outpatient diagnoses started in 2001 and is still not complete from all counties, that only specialist physician treatment is entered into the Patient Register, and that some individuals (e.g., patients with more severe ADHD or living in lower socioeconomic status neighborhoods) might be more likely to be convicted when caught. We tried to address selection biases by doing sensitivity analyses in different cohorts and with varying outcomes. All analyses suggested rate reductions of $17-46 \%$, reducing the likelihood that our results are due to selection effects.

Overall rates of crime and their resolution are mostly similar across Western Europe ${ }^{36}$, whereas comparisons with the US are more difficult due to differences in legal and judicial systems. Police-recorded assault rates were 3.7 per 1,000 population in the US and 4.1 in Sweden during 1981-199937. Even though the prevalence of ADHD diagnosis and medication varies between countries and over time, Sweden does not appear to be unusual in rates of ADHD and ADHD-medication ${ }^{38,39}$. The Swedish Medical Products Agency recommends pharmacological treatment for ADHD only when other supportive interventions have failed, indicating that pharmacological ADHD treatment most likely represent an indicator of the more severe cases of ADHD. Regardless, we cannot address whether the associations are the same in other cultures, and thus generalizations should be made with caution.

\section{Conclusion}

Among patients with ADHD, we found an inverse association between pharmacological treatment for ADHD and the risk of criminality. Potential beneficial effects would have to be carefully weighed against potential adverse effects of medication, including overprescription and side effects ${ }^{31,33}$. 


\section{Supplementary Material}

Refer to Web version on PubMed Central for supplementary material.

\section{Acknowledgments}

This study was supported in part by the Swedish Research Council, Swedish Council for Working Life and Social Research, the Swedish Prison and Probation Services, and National Institute of Child Health and Human Development (HD061817). SF is supported by the Welcome Trust.

\section{References}

1. Polanczyk G, de Lima MS, Horta BL, Biederman J, Rohde LA. The worldwide prevalence of ADHD: a systematic review and metaregression analysis. Am J Psychiatry. 2007; 164:942-8. [PubMed: 17541055]

2. Pastor PN, Reuben CA. Diagnosed attention deficit hyperactivity disorder and learning disability: United States, 2004-2006. Vital Health Stat. 2008; 10:1-14.

3. Barkley RA, Fischer M, Smallish L, Fletcher K. Young adult follow-up of hyperactive children: antisocial activities and drug use. Journal of child psychology and psychiatry, and allied disciplines. 2004; 45:195-211.

4. Satterfield JH, Faller KJ, Crinella FM, Schell AM, Swanson JM, Homer LD. A 30-year prospective follow-up study of hyperactive boys with conduct problems: adult criminality. Journal of the American Academy of Child and Adolescent Psychiatry. 2007; 46:601-10. [PubMed: 17450051]

5. Angold A, Costello EJ, Erkanli A. Comorbidity. Journal of child psychology and psychiatry, and allied disciplines. 1999; 40:57-87.

6. Banaschewski T, Coghill D, Santosh P, et al. Long-acting medications for the hyperkinetic disorders. A systematic review and European treatment guideline. European Child \& Adolescent Psychiatry. 2006; 15:476-95. [PubMed: 16680409]

7. Findling RL. Evolution of the treatment of attention-deficit/hyperactivity disorder in children: a review. Clin Ther. 2008; 30:942-57. [PubMed: 18555941]

8. Greenhill L, Kollins S, Abikoff H, et al. Efficacy and safety of immediate-release methylphenidate treatment for preschoolers with ADHD. Journal of the American Academy of Child and Adolescent Psychiatry. 2006; 45:1284-93. [PubMed: 17023867]

9. Adler LA, Zimmerman B, Starr HL, et al. Efficacy and safety of OROS methylphenidate in adults with attention-deficit/hyperactivity disorder: a randomized, placebo-controlled, double-blind, parallel group, dose-escalation study. J Clin Psychopharmacol. 2009; 29:239-47. [PubMed: 19440077]

10. Koesters M, Becker T, Kilian R, Fegert JM, Weinmann S. Limits of meta-analysis: methylphenidate in the treatment of adult attention-deficit hyperactivity disorder. $\mathrm{J}$ Psychopharmacol. 2009; 23:733-44. [PubMed: 18562416]

11. Kooij SJ, Bejerot S, Blackwell A, et al. European consensus statement on diagnosis and treatment of adult ADHD: The European Network Adult ADHD. BMC Psychiatry. 2010; 10:67. [PubMed: 20815868]

12. Biederman J, Petty CR, Evans M, Small J, Faraone SV. How persistent is ADHD? A controlled 10-year follow-up study of boys with ADHD. Psychiatry Res. 2010; 177:299-304. [PubMed: 20452063]

13. Adler LD, Nierenberg AA. Review of medication adherence in children and adults with ADHD. Postgrad Med. 2010; 122:184-91. [PubMed: 20107302]

14. Zetterqvist J, Asherson P, Halldner L, Långström N, Larsson H. Stimulant and non-stimulant ADHD drug use: Total population study of trends and discontinuation patterns 2006-2009. Acta Psychiatr Scand. In press.

15. McCarthy S, Asherson P, Coghill D, et al. Attention-deficit hyperactivity disorder: treatment discontinuation in adolescents and young adults. The British journal of psychiatry : the journal of mental science. 2009; 194:273-7. [PubMed: 19252159] 
16. The MTA Cooperative Group. A 14-month randomized clinical trial of treatment strategies for attention-deficit/hyperactivity disorder. The MTA Cooperative Group. Multimodal Treatment Study of Children with ADHD. Archives of General Psychiatry. 1999; 56:1073-86. [PubMed: 10591283]

17. Arnold LE, Chuang S, Davies M, et al. Nine months of multicomponent behavioral treatment for ADHD and effectiveness of MTA fading procedures. Journal of abnormal child psychology. 2004; 32:39-51. [PubMed: 14998110]

18. Jensen PS, Arnold LE, Swanson JM, et al. 3-year follow-up of the NIMH MTA study. Journal of the American Academy of Child and Adolescent Psychiatry. 2007; 46:989-1002. [PubMed: 17667478]

19. Molina BS, Flory K, Hinshaw SP, et al. Delinquent behavior and emerging substance use in the MTA at 36 months: prevalence, course, and treatment effects. Journal of the American Academy of Child and Adolescent Psychiatry. 2007; 46:1028-40. [PubMed: 17667481]

20. Swanson J, Arnold LE, Kraemer H, et al. Evidence, interpretation, and qualification from multiple reports of long-term outcomes in the Multimodal Treatment study of Children With ADHD (MTA): part I: executive summary. J Atten Disord. 2008; 12:4-14. [PubMed: 18573923]

21. Ludvigsson JF, Otterblad-Olausson P, Pettersson BU, Ekbom A. The Swedish personal identity number: possibilities and pitfalls in healthcare and medical research. European journal of epidemiology. 2009; 24:659-67. [PubMed: 19504049]

22. Ludvigsson JF, Andersson E, Ekbom A, et al. External review and validation of the Swedish national inpatient register. BMC Public Health. 2011; 11:450. [PubMed: 21658213]

23. Wettermark B, Hammar N, Fored CM, et al. The new Swedish Prescribed Drug Register-opportunities for pharmacoepidemiological research and experience from the first six months. Pharmacoepidemiol Drug Saf. 2007; 16:726-35. [PubMed: 16897791]

24. BRÅ., editor. Kriminalstatistik 2010 [Criminal statistics]. Västerås; 2011.

25. Fazel S, Grann M. The population impact of severe mental illness on violent crime. Am J Psychiatry. 2006; 163:1397-403. [PubMed: 16877653]

26. Snappin MS, Jiang Q, Iglewicz B. Illustrating the impact of a time-varying covariate with an extended Kaplan-Meier estimator. The American Statistician. 2005; 59:301-307.

27. Allison, PD. Fixed effects regression models. Sage Publications; Thousand Oaks: 2009.

28. Lee, EW.; Wei, LJ.; Amato, DA. Cox-type regression for large numbers of small groups of correlated failure time observations. In: Klein, JP.; Goel, PK., editors. Survival Analysis: State of the Art. Kluwer Academic; Dordrecht: 1992. p. 237-247.

29. Lindevall, O. European Society for Child and Adolescent Psychiatry. Budapest: 2009. Pastill - A Comprehensive Clinical Database for Child and Adolescent Psychiatry in Stockholm.

30. Cole SR, Platt RW, Schisterman EF, et al. Illustrating bias due to conditioning on a collider. International Journal of Epidemiology. 2010; 39:417-20. [PubMed: 19926667]

31. Graham J, Coghill D. Adverse effects of pharmacotherapies for attention-deficit hyperactivity disorder: epidemiology, prevention and management. CNS Drugs. 2008; 22:213-37. [PubMed: 18278977]

32. Singh I. Beyond polemics: science and ethics of ADHD. Nat Rev Neurosci. 2008; 9:957-64. [PubMed: 19020513]

33. Winhusen TM, Lewis DF, Riggs PD, et al. Subjective effects, misuse, and adverse effects of osmotic-release methylphenidate treatment in adolescent substance abusers with attention-deficit/ hyperactivity disorder. J Child Adolesc Psychopharmacol. 2011; 21:455-63. [PubMed: 22040190]

34. Gibbons RD, Amatya AK, Brown CH, et al. Post-approval drug safety surveillance. Annu Rev Public Health. 2010; 31:419-37. [PubMed: 20070192]

35. Chamberlain SR, Robbins TW, Sahakian BJ. The neurobiology of attention-deficit/hyperactivity disorder. Biological psychiatry. 2007; 61:1317-9. [PubMed: 17556026]

36. Dolmén, L. Brottsligheten i olika länder [Criminality in different countries]. National Council for Crime Prevention; Stockholm: 2001.

37. Farrington, D.; Langan, P.; Tonrym, M., editors. Cross-national studies in crime and justice. US Department of Justice, Bureau of Justice Statistics; Washington, DC: 2004. 
38. Zoega H, Furu K, Halldorsson M, Thomsen PH, Sourander A, Martikainen JE. Use of ADHD drugs in the Nordic countries: a population-based comparison study. Acta psychiatrica Scandinavica. 2011; 123:360-7. [PubMed: 20860726]

39. Scheffler RM, Hinshaw SP, Modrek S, Levine P. The global market for ADHD medications. Health Aff (Millwood). 2007; 26:450-7. [PubMed: 17339673] 


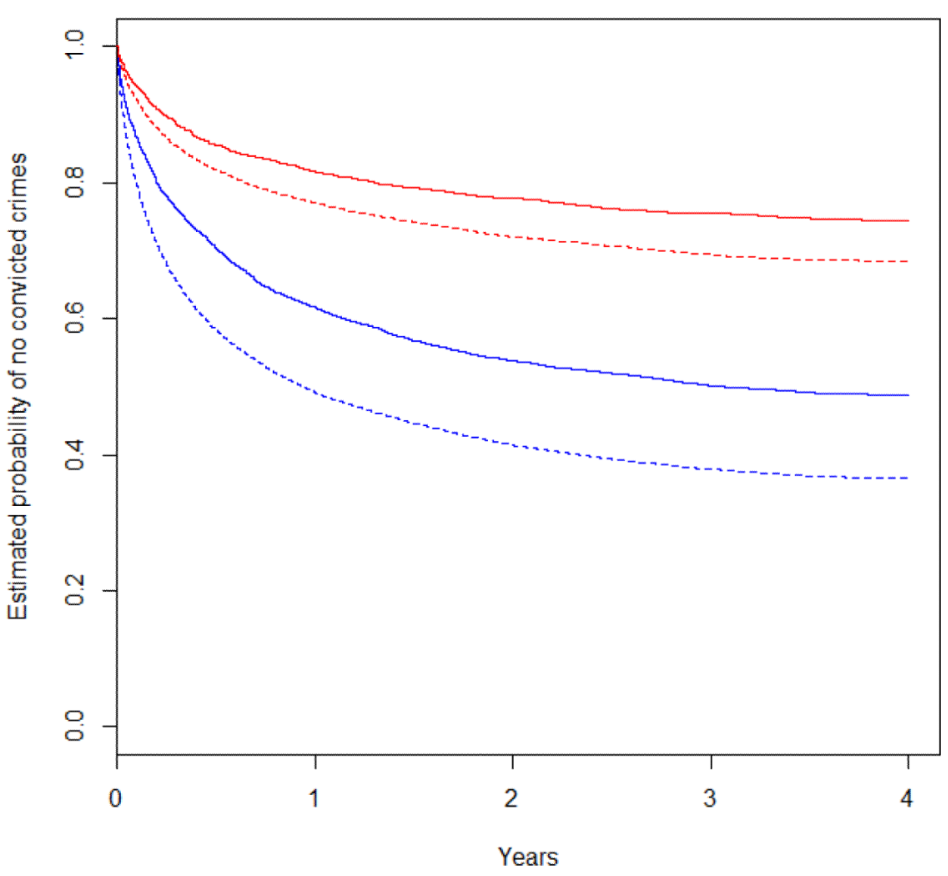

Figure 1.

Extended Kaplan-Meier curves for patients in the Swedish Patient Register diagnosed with ADHD and born 1990 or earlier, by sex and medication status.

Footnote: Blue lines are for men and red lines for women. Solid lines are for medication and dashed lines are for no medication.

The 16,087 men contributed to 56,227 periods and 23,693 convictions (on average 3.5 periods of medication/non-medication and 1.5 convictions). The 9,599 women contributed to 23,533 periods and 4,112 convictions (on average 2.5 periods of medication/nonmedication and 0.4 convictions). 


\section{Table 1}

Characteristics at baseline and ADHD medication and criminal convictions during follow-up among patients in the Swedish Patient Register diagnosed with ADHD born 1990 or earlier.

\begin{tabular}{|c|c|c|}
\hline & Men & Women \\
\hline $\mathbf{N}$ & 16,087 & 9,569 \\
\hline Person years at risk & 62,637 & 37,963 \\
\hline \multicolumn{3}{|c|}{ Characteristics at baseline } \\
\hline \multicolumn{3}{|l|}{ Age distribution } \\
\hline $15-24(\%)$ & $54.3 \%$ & $46.3 \%$ \\
\hline $25-39(\%)$ & $30.0 \%$ & $35.4 \%$ \\
\hline 40 or older $(\%)$ & $15.7 \%$ & $18.3 \%$ \\
\hline \multicolumn{3}{|l|}{ Civil status } \\
\hline$\%$ Unmarried & $85.7 \%$ & $73.4 \%$ \\
\hline$\%$ Married & $7.5 \%$ & $13.1 \%$ \\
\hline$\%$ Divorced & $6.7 \%$ & $13.2 \%$ \\
\hline$\%$ Widowed & $0.1 \%$ & $0.4 \%$ \\
\hline$\%$ living in an metropolitan area & $14.8 \%$ & $15.1 \%$ \\
\hline$\%$ in employment & $24.3 \%$ & $25.6 \%$ \\
\hline$\%$ studying & $29.2 \%$ & $29.5 \%$ \\
\hline Median family income in \$ US & 27500 & 26500 \\
\hline \multicolumn{3}{|l|}{ Other psychotropic medications } \\
\hline$\%$ antipsychotics & $11.9 \%$ & $13.1 \%$ \\
\hline$\%$ hypnotics/anxiolytics & $27.3 \%$ & $39.1 \%$ \\
\hline$\%$ antidepressants & $28.7 \%$ & $45.1 \%$ \\
\hline$\%$ drugs used in addictive disorders & $4.6 \%$ & $3.1 \%$ \\
\hline$\%$ Mood stabilizers/anti-epileptics & $8.2 \%$ & $11.1 \%$ \\
\hline \multicolumn{3}{|c|}{ ADHD medication and criminal convictions during follow-up } \\
\hline$\%$ ADHD medication & $53.6 \%$ & $62.7 \%$ \\
\hline$\%$ Convicted for any crime & $36.6 \%$ & $15.4 \%$ \\
\hline$\%$ Less severe crimes $\$$ & $34.4 \%$ & $15.0 \%$ \\
\hline$\%$ Violent and sexual crime & $14.7 \%$ & $3.6 \%$ \\
\hline - homicide & $0.13 \%$ & $0.04 \%$ \\
\hline - assault & $9.3 \%$ & $2.0 \%$ \\
\hline - threat/harassment & $6.3 \%$ & $1.1 \%$ \\
\hline - threat/assult directed to a public servant & $3.2 \%$ & $1.1 \%$ \\
\hline - robbery & $1.6 \%$ & $0.0 \%$ \\
\hline - arson & $0.2 \%$ & $0.1 \%$ \\
\hline - sexual crimes & $0.7 \%$ & $0.0 \%$ \\
\hline$\%$ substance-related crime & $20.5 \%$ & $7.9 \%$ \\
\hline - drug offenses & $17.7 \%$ & $7.2 \%$ \\
\hline
\end{tabular}




\begin{tabular}{|l|c|c|}
\hline & Men & Women \\
\hline - driving under influence & $9.4 \%$ & $2.5 \%$ \\
\hline
\end{tabular}

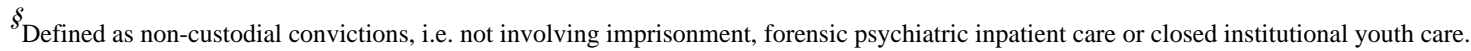




\section{Table 2}

Criminality rate for any crime 2006-2009 during treatment periods compared to non-treatment periods among patients in the Swedish Patient Register diagnosed with ADHD born 1990 or earlier.

\begin{tabular}{|c|c|c|c|c|c|c|}
\hline \multirow[t]{3}{*}{ Sex } & \multirow[b]{3}{*}{$\begin{array}{l}\text { Number of } \\
\text { patients }\end{array}$} & & \multicolumn{4}{|c|}{ Criminality rate ratio } \\
\hline & & & \multicolumn{2}{|c|}{ Cox Regression } & \multicolumn{2}{|c|}{ Stratified Cox Regression ${ }^{*}$} \\
\hline & & $\begin{array}{l}\text { Number of } \\
\text { crimes }\end{array}$ & Hazard ratio & $\begin{array}{c}95 \% \\
\text { Confidence } \\
\text { interval }\end{array}$ & Hazard ratio & $\begin{array}{c}95 \% \\
\text { Confidence } \\
\text { interval }\end{array}$ \\
\hline Males & 16,087 & 23,693 & 0.70 & $0.66-0.75$ & 0.68 & $0.63-0.73$ \\
\hline Females & 9,569 & 4,112 & 0.78 & $0.68-0.90$ & 0.59 & $0.50-0.70$ \\
\hline
\end{tabular}

*Within-individual rate ratio (i.e. the hazard of committing a crime while on ADHD medication compared to the same individual while not on medication) 


\section{Table 3}

Differences in risk of a criminal conviction between two consecutive periods (a period without ADHD medication compared to a period with ADHD medication) for patients who changed their medication status.

\begin{tabular}{|l|c|c|c|c|c|c|c|c|c|}
\hline Treatment period & \multicolumn{3}{|c|}{ Two consecutive periods } & \multicolumn{3}{c|}{$\begin{array}{c}\text { From no medication to } \\
\text { medication }\end{array}$} & \multicolumn{3}{c|}{$\begin{array}{c}\text { From medication to no } \\
\text { medication }\end{array}$} \\
\hline & $\mathbf{N}$ & $\begin{array}{c}\text { Risk } \\
\text { Difference } \\
(\%)\end{array}$ & $\mathbf{9 5} \% \mathbf{C I}$ & $\mathbf{N}$ & $\begin{array}{c}\text { Risk } \\
\text { Difference } \\
(\%)\end{array}$ & $\mathbf{9 5} \% \mathbf{C I}$ & $\mathbf{N}$ & $\begin{array}{c}\text { Risk } \\
\text { Difference } \\
(\%)\end{array}$ & $\mathbf{9 5} \%$ CI \\
\hline All treatment periods & 7,895 & 12.0 & $11.8-12.3$ & 7,189 & 15.8 & $15.4-16.1$ & 4,736 & 6.5 & $6.2-6.9$ \\
\hline $\begin{array}{l}\text { First treatment period } \\
\text { only }\end{array}$ & 7,398 & 10.4 & $10.1-10.7$ & 6,105 & 13.7 & $13.3-14.1$ & 4,413 & 5.7 & $5.3-6.2$ \\
\hline $\begin{array}{l}\text { Second treatment } \\
\text { period only }\end{array}$ & 1,807 & 9.8 & $9.3-10.4$ & 1,788 & 12.0 & $11.3-12.7$ & 1,030 & 6.3 & $5.5-7.1$ \\
\hline
\end{tabular}


Table 4

Sensitivity analyses. Rate ratios for different criminal outcomes 2006- 2009 in various cohorts of men with ADHD.

\begin{tabular}{|c|c|c|c|c|c|c|}
\hline \multirow[t]{2}{*}{ Type of cohort } & \multirow[b]{2}{*}{$\begin{array}{l}\text { Type of } \\
\text { exposure }\end{array}$} & \multirow[b]{2}{*}{$\begin{array}{l}\text { Type of } \\
\text { criminal } \\
\text { outcome }\end{array}$} & \multirow[b]{2}{*}{$\begin{array}{l}\text { Number of } \\
\text { individuals }\end{array}$} & \multirow[b]{2}{*}{$\begin{array}{l}\text { Number of } \\
\text { crimes }\end{array}$} & \multicolumn{2}{|c|}{ Criminality rate ratio } \\
\hline & & & & & Hazard ratio & $\begin{array}{c}95 \% \text { Confidence } \\
\text { interval }\end{array}$ \\
\hline $\begin{array}{l}\text { ADHD diagnosed in Patient } \\
\text { Register }\end{array}$ & Stimulant $^{\dagger}$ & $\begin{array}{l}\text { Any criminal } \\
\text { conviction }\end{array}$ & 16,087 & 23,693 & 0.66 & $0.61-0.71$ \\
\hline $\begin{array}{l}\text { ADHD diagnosed in Patient } \\
\text { Register }\end{array}$ & $\begin{array}{l}\text { ADHD } \\
\text { medication }\end{array}$ & Violent crime & 16,087 & 3,985 & 0.54 & $0.44-0.67$ \\
\hline $\begin{array}{l}\text { ADHD diagnosed in Patient } \\
\text { Register }\end{array}$ & $\begin{array}{l}\text { ADHD } \\
\text { medication }\end{array}$ & $\begin{array}{l}\text { Less severe } \\
\text { crime } \mathcal{\xi}\end{array}$ & 16,087 & 17,421 & 0.67 & $0.62-0.73$ \\
\hline Prescribed ADHD medication ${ }^{*}$ & $\begin{array}{l}\text { ADHD } \\
\text { medication }\end{array}$ & $\begin{array}{l}\text { Any criminal } \\
\text { conviction }\end{array}$ & 17,141 & 27,416 & 0.64 & $0.60-0.68$ \\
\hline $\begin{array}{l}\text { ADHD diagnosed in child and } \\
\text { adolescent mental health services } \\
\text { (Pastill Register) }\end{array}$ & $\begin{array}{l}\text { ADHD } \\
\text { medication }\end{array}$ & $\begin{array}{l}\text { Any criminal } \\
\text { conviction }\end{array}$ & 1,090 & 995 & 0.83 & $0.54-1.29$ \\
\hline $\begin{array}{l}\text { Individuals with conduct, } \\
\text { oppositional defiant, antisocial } \\
\text { personality, or substance abuse } \\
\text { disorders diagnoses excluded }\end{array}$ & $\begin{array}{l}\text { ADHD } \\
\text { medication }\end{array}$ & $\begin{array}{l}\text { Any criminal } \\
\text { conviction }\end{array}$ & 9,801 & 5,723 & 0.77 & $0.66-0.90$ \\
\hline $\begin{array}{l}\text { ADHD diagnosed in Patient } \\
\text { Register }\end{array}$ & $\begin{array}{l}\text { ADHD } \\
\text { medication }\end{array}$ & $\begin{array}{l}\text { Suspected of } \\
\text { crime }\end{array}$ & 16,087 & 55,953 & 0.81 & $0.77-0.84$ \\
\hline
\end{tabular}

* ADHD medication identified through the Prescribed Drug Register (ATC-codes N06BA04, N06BA09, N06BA01, N06BA02).

${ }^{\dagger}$ Not controlling for other concomitant ADHD medications.

${ }^{\mathcal{B}}$ Defined as non-custodial convictions, i.e. not involving imprisonment, forensic psychiatric inpatient care or closed institutional youth care. 